\title{
Stage IB Ampulla of Vater Cancer AJCC v8
}

National Cancer Institute

\section{Source}

National Cancer Institute. Stage IB Ampulla of Vater Cancer A/CC v8. NCI Thesaurus.

Code C134868.

Stage IB includes: (T1b, N0, M0); (T2, NO, M0). T1b: Tumor invading beyond the sphincter of Oddi (perisphincteric invasion) and/or into the duodenal submucosa. T2:

Tumor invading into the muscularis propria of the duodenum. NO: No regional lymph node metastasis. M0: No distant metastasis. (AJCC 8th ed.) 